\title{
Incorporating Sustainability into Real Estate Valuation: the Perception of Nigerian Valuers
}

\author{
Dr. G.K. Babawale (Corresponding author) \\ Department of Estate Management \\ University of Lagos, Akoka, Yaba, Lagos, Nigeria \\ Tel: 234-80-2316-6473Ｅ-mail: gkbabs@yahoo.co.uk \\ Basirat A. Oyalowo \\ Department of Estate Management \\ University of Lagos, Akoka, Yaba, Lagos, Nigeria \\ Tel: 234-80-7449-6369 E-mail:boyalowo@yahoo.com
}

Received: April 6, 2011

Accepted: June 11, 2011

doi:10.5539/jsd.v4n4p236

\begin{abstract}
The paper appraises the perception of real estate valuers' of sustainability in real estate valuation in Nigeria. The study was based on a survey of one hundred and sixty estate surveyors and valuers who were asked, among others, to rate the significance of a range of sustainability features on the market value of a hypothetical property based on the social, economic and environmental features that constitute the triple bottom line of sustainability. The study presents evidence that, even in a developing country like Nigeria, there is already a growing awareness of the need to mainstream sustainability into real estate valuation practice though respondents tended to define real estate sustainability in terms of its social, rather than economic or environmental features. It is suggested that Nigerian valuers must improve on their present knowledge of sustainability to effectively account for all three features in their valuations. Investors, property occupiers, the government and estate surveyor and valuers (appraisers) were identified as the principal drivers of the sustainability crusade in the country.
\end{abstract}

Keywords: Real estate, Valuation, Sustainability, Valuers' perception, Nigeria

\section{Introduction}

Sustainable development is development that meets the need of the present without compromising the ability of future generation to meet their own needs (WCED, 1987). Within efforts undertaken by the global community to achieve more sustainable development, probably no sector has a greater potential role as property and construction (Lorenz, 2006). For instance, in the OECD countries alone, the built environment is responsible for between 24 to 40 per cent of total energy use, 30 per cent of raw energy use, 30 to 40 per cent of solid waste generation (OECD, 2003). Thus, property and construction has the largest single share in global environmental degradation and impairment of human well-being. Unfortunately, actors within the property market, including real estate valuers and analysts, are slowest in responding to challenges imposed by sustainable development (Lorenz, 2006).

It is argued that success in achieving more sustainable development in property and construction largely depends on progresses in integrating sustainability issues into property valuation theory and practice (Lorenz, 2006). Unless and until valuers began to reflect and account for sustainability features in the values of property, investors may not be motivated to incorporate sustainability features into property development. Adequate pricing of externalities will have impact on both people's behavior and the improvement of the environment (Pearse, 2005).

This study analyzed the perception of sustainability in real estate valuation from the view-point of sampled Nigerian real estate valuers operating in three chief administrative, commercial and industrial cities - Lagos, Port Harcourt, and Abuja. This is done by highlighting the sustainability features that the valuers consider most significant in the valuation of a hypothetical sustainable property and thereby providing a gauge of the valuers' appreciation of the sustainable real estate movement, its implications on the appraisal process, and on the general workings of the property market. The study is justified on a number of grounds. The study attempted an assessment of the capability of Nigerian valuers to reflect sustainability in their valuations. In the ongoing global drive for sustainability, it is imperative that Nigerian valuers, like their peers in other parts of the world, appreciate the effects of sustainability features in property and also acquire the skill to account for them in their valuations. This study is also a cognate contribution to knowledge as the area of discourse is relatively academically recent with only a few empirical investigations to date (Sayce et al., 2010). It is in part an answer to the current global call for better links between property investment, social responsibility and sustainability (Pivo, 2007). The study also made a modest contribution to the ongoing controversy on the conventional versus 
contemporary methods as the more appropriate valuation method for reflecting sustainability features in properties.

The study hypothesized that Nigerian valuers do not recognize sustainability features in properties; that Nigerian valuers would not utilize any of the modern methods to value for sustainability; and that Nigerian appraisers do not require additional training to carry out successful sustainable valuations.

The paper is in five sections. This introductory section is followed by the section on literature review. The literature review section is followed by a description of the study area and study methodology. Section four deals with data analysis and the discussion of the results, while the last section contains the conclusions and recommendations.

\section{Review of Literature}

A recent estimate puts the world's wealth at $\$ 48$ trillion, of which approximately half is real estate (Lynch \& Gemini, 2007). In most countries land accounts for between half and three quarters of national wealth. Property provides space for living and recreation. Production and other economic activities also take place on real property. Property also constitutes a major part of assets value in companies' balance sheets and is extensively used as collateral for corporate debt. Property is the commonest form of asset held by corporate bodies and individual investors. The place of real property in the economic growth and overall well being of any nation cannot be overemphasized therefore. This however comes at a cost. Properties are not known to be socially and environmentally benign commodities (Lorenz, 2006; Pivo, 2005, 2007). The real estate industry is a major source of negative environmental impacts contributing significantly to raw material depletion, harmful gas emissions, solid waste generation and energy use (Addae-Dapaah et al., 2009; Goering, 2009; Robinson, 2005; Lorenz, 2006).

The peculiar nature of properties and the impact of their construction on the environment suggest that sustainability should be a major priority for policy makers and investors. However, some peculiarities of the property market pose some challenges to widespread acceptance of the concept in the property investment, construction and appraisal sectors. For instance, In GVA-Grimley's (2008) survey of UK's leading institutions and investors on attitudes to sustainability investment showed that the value of environmental sustainability is not appreciated by either lenders or valuers. Lenders, as well as property appraisers also appeared unsure about the impact of environmental benefits on the buildings (Fuerst and McAllister, 2010). Thus, sustainability is not reflected in valuations with the danger that sustainable properties remain undervalued. The impact of this on real estate investment and financial decisions is to reduce the potential stream of funds into the sector, among others. Robinson (2005) noted that the mismatch between investment returns and funding ensures that short term gains are paramount considerations in property investment. Therefore, issues relating to non-economic sustainability returns might not be attractive to the real estate investment community and this jeopardizes attempts to mainstream sustainability in the industry.

Property valuations represent a vital link between market value, property performance and the adoption of sustainability in real estate (Sayce et al., 2010). Thus, if major sustainability-related benefits/risks associated with ownership and use of properties are not captured in property valuations; there is a risk that investment decisions (supplied by uninformed mainstream financial professionals) are being made on the basis of incorrect and distorted valuations (Lorenz, 2006).

In the current discourse, it is possible to ascribe two possibilities to the concept of sustainability in real estate valuation - valuing sustainable properties, and assessing for sustainability in properties. The first refers to valuation of a property that has been built with sustainable features and operating in a sustainable sub-market, with the valuation method and approach taking account of the impact of these features on the property's performance. The major challenge that confronts a valuer when appraising this category of property is how to find comparable sales prices and the carrying out necessary adjustments while using the conventional valuation methods such as the comparable sales method (Lorenz, 2006). Here, recognition, identification and adoption of indicators of sustainability in the valuation method are essential. In the second case, whether sustainable or not, properties will be valued against a set of benchmarks that show their degree of balance of economic and social performance with environmental protection. This, according to Boyd (2005) is the triple bottom line valuation approach which recognizes that property development and management should be evaluated against criteria that embody sustainability. The challenge that valuers include that of identifying the physical characteristics and attributes of the subject property (Lorenz, 2006).

From the foregoing, a change in the way property appraisal is carried out has become inevitable. A whole new world of property appraisal will emerge with the development of sustainable property sub-markets, tools, indicators, valuation techniques and approaches. The new world demands professional valuers who, through the quality of their advice, are able to reflect authoritatively the true value that sustainability adds to properties. Interestingly, a number of studies have been carried out to facilitate this change. For instance, Pivo (2007) examined the development of sustainability indicators; while Boyd (2005) and Lorenz (2006) debated on appropriate methodologies. Though it is agreed that attention to environmental and social features were 
positively perceived by both occupiers and investors of sustainable properties (Boyd, 2005; Lutzendorf and Lorenz, 2005; Sayce, Ellison, and Smith, 2004; Kimmet, 2006), the question of how to quantify and reflect these impacts in the real estate valuation process remains unsettled. While some authors like Boyd (2005), Pivo (2005), and Robinson (2005), argued that traditional methods are applicable; others such as Lorenz (2006) are of the opinion that traditional methods will only lead to unbalanced value estimates.

In supporting his position, Boyd (2005) presents a study of the impact of environmental and social sustainability on economic returns. By this, he attempts to capture the interactions of the triple-bottom line on property investment, and at the same time, ascertaining whether it is possible to quantify the impact of environmental and social characteristics on investment property. Ultimately, the study tested whether these features would bring appreciable economic returns to the investor. To achieve this, he utilized a case-study valuation of a 10 year-old prime office building in Brisbane, Australia, using the traditional discounted cash flow (DCF) method. He applied this method in a simulation exercise to determine the difference between the returns achievable on an existing prime grade office property and a similar environmentally and socially enhanced building. This requires testing the model on the cash-flow of the building over a seven-year period under four conditions ranging from the building in existing condition, the building with socially enhanced features, the building with environmentally enhanced features, and the building with both environmentally and socially enhanced environmental features. The study showed the greatest impact was for the building with enhanced features; with IRR increasing from $9.53 \%$ (in its unenhanced state) to $9.70 \%$. This compares with $9.26 \%$ for building with enhanced social features and $9.32 \%$ for buildings with both enhanced environmental and social features. This suggests that environmental considerations appealed to the respondents above social features and even above environmental and social factors combined. However, because these changes are still minimal, Boyd concluded that the market showed an indication of future demand for enhanced properties. He also concluded on the basis of the experiment, that the application of traditional valuation methods in the assessment of the impact of the triple bottom-line is indeed achievable.

With regards to economic sustainability, Rothschild (2005), (as cited by Kauko, 2008) while agreeing with earlier studies asserted that economic sustainability cannot be measured through economic efficiency, but rather through economic security and quality of life. Kauko (2008) posited that instead of evolving tools for valuing sustainable real estates, attention should be given to the valuation of sustainable markets. This is based on the premise that sustainable markets, defined through sustainable demand, supply, prices and values, would generate sustainable value, which could then be used as an indicator for sustainability. The ultimate goal is to ensure that quality increases, just as price level increases. This is the concept of economic sustainability. Kauko (2008) thereafter proposed the measurement (or appraisal) of the economic sustainability of residential real estate by correlating the monetary price of the development with measurements of non-monetary quality as well as affordability and welfare indices. He argued that the most sustainable residential property markets are those where price increases are balanced by an increase in the quality of life, thus producing an economically efficient and economically sustainable real estate market compared to other submarkets in the $3 \times 3$ quadrant where price increases are not matched by quality increases and where quality decreases with price decreases.

The implication (and appeal) of the empirical property modeling proposed by Kauko (2008) is that where markets are classified as sustainable, added value would be brought to the properties. Thus, sustainability valuation would be tied to the local market conditions. It would therefore be possible to ascribe values to properties based on the sustainability submarket to which they belong. An empirical sustainability property market modeling can subsequently be developed on this basis. For this to happen, real estate markets have to be classified on the basis of their sustainability. However, the challenge of how to locate and value for sustainability in the market remains. A number of suggestions have been made to ensure that this is achieved. First, Kauko (2008) suggests that a penalty or bonus be added on the observed price in sustainable property transactions. A penalty will be deducted if the building is considered unsustainable and a bonus will be added if the building is considered sustainable. It is thereafter assumed that as new real estate developments occur, this method of valuation would be adopted for transactions in that market. Thus, a database of valuations in a sustainable market context can be built up which can be used as a basis for comparative appraisal.

Kimmet (2006) study on psychic income analysis could potentially contribute to the question of appropriate means of accounting for social sustainability. He argued that rather than focusing on appropriate valuation methodology, the adoption of a psychic income premium into valuation practice would deliver a more comprehensive account of social sustainability. Kimmet (2006) defines the psychic income of a provider as the financial premium paid by customers enjoying a psychic benefit. It is therefore possible to view the sustainable property investment market as a specialized market catering only for certain types of organizations that value such distinctions. This will supposedly ensure that a premium can be paid as the psychic income deriving from the use of such sustainable properties. This premium can then be factored into the valuation process, thereby making it easier to adopt any valuation approach as appropriate. The major contention against the theoretical foundation proposed by Kimmet (2006) is the ascription of monetary value to the psychic income and the basis of recognizing the indicators that measure it. More research has to be carried out in this regard. 
Using the concepts of price and worth, Robinson (2005) developed an outline valuation process to assist valuers in appraising environmental sustainability. Rent, capital growth and psychic income are the indicators of environmental sustainability in his study. A residual analysis of two hypothetical properties, a conventional office property and an environmentally sustainable property showed that the worth of the environmentally sustainable property building is substantially greater than the estimate of price commanded by the conventional building. This means that the application of the concept of worth into the traditional residual method of valuation would generate higher values and benefits for environmentally sustainable buildings. He however conceded that even though the concept can be readily accepted by owner-occupiers; its acceptance in the investment market depends on the ability of valuers to account for psychic income, improved rental values and technical performance of buildings and improvements in productivity and other occupants' advantages.

Lorenz (2006) provides a useful analysis of the appropriateness of both modern and traditional methods to sustainability valuation practice. He contends that traditional approaches are useful for the valuation of single properties and could therefore be adapted to value sustainable properties. On the other hand, modern methods such as hedonic pricing, fuzzy logic, and spatial analysis method are appropriate for mass valuations and so are best suited for valuing properties in a sustainable market. Lorenz (2006) particularly drew attention to the real options and hedonic pricing methods. The real options method is favored for valuing sustainability because it is designed to analyze future opportunities (rather than projecting from current and past transactions), that may arise from a particular parcel of land or building. It is therefore particularly suited to account for the increased flexibility and adaptability that sustainable properties have to offer. The hedonic pricing method, on the other hand, has the advantage of being user-friendly. It is useful in measuring the value that market participants place on different quantitative and qualitative property characteristics; making it easy to measure the relationship between sustainability of construction and observed property prices. Hence, a more scientific basis for the value adjustments necessary to carry out sustainable property valuations is offered. Availability of property transactions databases is however recognized as a major constraint against the use of modern methods in general and the hedonic pricing model in particular.

Putting all the studies highlighted above together, we could say that it is possible to value properties in sustainable properties markets with the use of either modern or conventional methods. In carrying out valuation using either method, the environmental, social and economic features indicating sustainability will be identified and applied in the manner suitable for each method. However, it is noticeable that development of indicators to capture each feature is quite problematic. It is also clear that the dearth of property transaction databases could impede the valuation process, besides the current small size of sustainable market. There are other constraints related to the practice particularly in an evolving market like Nigeria. For instance, there exists the problem of appropriately adjusting discount or capitalization rates to account for sustainability features in an environment that lacks comparative financial data, associated information on building performance and guidance and other essential data.

\section{Study Area}

The study covers Nigeria's three principal administrative, commercial and industrial cities - Lagos, Port Harcourt, and Abuja. Lagos metropolis has the most active property market with the highest average property value and stock of investment (Babawale and Koleoso, 2006). More than $90 \%$ of the headquarter offices of banks and insurance companies (notable end users of valuations) are located within the metropolis (Babawale, 2008). Portharcourt is the capital city of Nigeria's oil-rich Rivers State, Nigeria's chief city in the east, and the seat of several oil prospecting and allied companies with a vibrant property market. Abuja is Nigeria's federal capital territory with a rapidly developing property market.

The latest directory of the Nigerian Institution of Estate Surveyors and Valuers (2006) showed that approximately $70 \%$ of registered firms of Estate Surveyors and Valuers have either their head office or at least a branch office in one of the three cities covered by the study. This is made up of $52 \%$ in Lagos, $13 \%$ in Port Harcourt, and 7\% in Abuja. This suggests that a large proportion of both the providers and the end users of valuations are resident in the study area.

\section{Method of Study}

The study is based on a survey of one hundred and sixty estate surveyors and valuers practicing in Lagos metropolis, Port Harcourt and Abuja. Respondents were chosen by purposeful sampling technique based on locational clusters. This was done by locating the geographical clusters of firms of Estate Surveyors and Valuers which are to be found in clusters or pockets of settlements around major business districts of major urban centres (Babawale, 2008). This study identified four of such clusters in Lagos - Ikeja, Lagos Island, Victoria Island/Lekki and Surulere/Yaba. Two hundred and fifty (250) questionnaires were distributed in all out of which 160 were duly completed and returned. This represents $64 \%$ return rate.

In view of the nature of the study, a close-ended questionnaire in three sections was designed. Section one concerned the personal and professional data of the respondents. In section two, respondents were asked to rate the significance of 39 sustainability features on the market value of a hypothetical property. A five-point likert 
scale with 1 denoting 'not significant' to 5 denoting 'significant' was used. This method is considered appropriate having being used in a similar study (Addae-Dapaah et al., 2009).

To assess the weight attached to sustainability features, it is necessary to disaggregate each of the triple bottom-lines - social, environment and economic - into a constituent set of indicators. The generation of environmental indicators is relatively easy due to the scale of detailed research that has been carried out in the area in the recent past. However, the development of social and economic sustainability indicators presents special problems due to the paucity of data in this area. Thus, we have had to rely on variables employed in Boyd (2005). This offered several advantages. One, the study utilizes internationally recognized sustainability indicators, most of which had been pre-tested. This permits this study to be compared with other studies. Secondly, even though it is generally difficult to find market-based evidence of the impact of the triple bottom-line on the return from an investment property, these indicators were culled from market data available in Queensland, Australia for the "CRRC Construction Innovation Project" (2004). Third, while it is acknowledged that more indicators could be generated for any of the triple bottom-lines, it was considered expedient, due to the scale of this research, to rely on available, pretested and applicable indicators from a previous study. Lastly, it is acknowledged that advanced countries had established and are testing for environmental compliance in the design and construction of new investment and residential properties (Australia has the 'Green Star Rating', USA has 'Leadership in Energy and Environmental Design Assessment Method 'BREEAM'); this study was tailored to reflect not only environmental sustainability but also social and economic sustainability; all of which were addressed by Boyd (2005). However, in agreement with the argument that the specification of these indicators can take the form that reflects the operational nature of the property, the utility of the structure as well as the market's perception of valuers of the individual measures (Boyd, 2005), we have adjusted the classifications slightly to reflect local perception and attributes. Environmental sustainability has been divided into two namely: design/construction environmental features and green environmental features. This was done to simplify the questionnaire and ensure that respondents are able to differentiate between these features ${ }^{1}$. From the original 47 features in Boyd's work, we have combined a few to mitigate the influence of some variables that were confirmed too foreign to be applicable to this effort by respondents during the pilot study for this paper. A total of 39 variables were thus considered (see Table 1).

\section{Data Presentation and Discussions}

The data analysis has been structured into two sections. In the first section is the analysis of the data on the characteristics of the respondents which were presented using descriptive statistics. The second is the analysis of variables using Principal Component Analysis as a tool to demonstrate the weight attached to each cluster of sustainability features. All analyses were carried out with the aid of SPSS.17.

\subsection{Characteristics of Respondent Estate Surveyors and Valuers}

The relatively high proportion of male respondents $(68 \%)$ in Table 2 reflects the labor force participation rate of males and females in the profession. Majority of the respondents $(84 \%)$ were graduates (university or polytechnic); and $80 \%$ were in the "associate" category of the membership hierarchy of the Nigerian Institution of Estate Surveyors and Valuers (NIESV). Only 12\% had over 6 years experience, suggesting that most of the respondents are young in the profession and probably young in age. Of the 160 respondents, $24 \%$ were based in Ikeja, 19\% in Lagos Island, 16\% operated within Victoria Island-Lekki axis, $8 \%$ were based in Surulere, while $13 \%$ were based in other parts of Lagos metropolis. Of the remaining $20 \%, 7 \%$ practiced in Port Harcourt and $13 \%$ in Abuja.

\subsection{Principal Component Analysis}

The preferred method of statistical analysis is the Principal Component Analysis (PCA) with varimax rotation. Studies with similar themes as the present one have adopted it. For instance, Zemeering (2009) adopted it in ascertaining the perception of government workers to sustainability programs in the US. Addae-Dappah et al (2009) employed it in assessing the perception of investors and users to sustainable property features in Singapore while Oven and Pekdemir (2006) utilized the same technique in establishing office rents determinants in Istanbul. PCA investigates the number of variables that represents a large portion of the total variance $(>70 \%)$ and designates them as the core determining factors.

The appropriateness of the data was at first confirmed through the Kaiser- Meyer-Olkin (KMO) measure of sampling adequacy, which yielded a score of 0.666 (see Table 2) which is considered high enough and appropriate (Kaiser, 1970, Addae-Dappah et al., 2009).

In order to carry out the PCA, a correlation matrix was generated for the 39 variables. Then, factors were extracted from the correlation matrix based on their correlation coefficients with the variables. Thirdly, the factors were rotated in order to maximize the relationship between the variables and the factors. The first un-extracted analysis showed that there was presence of multi-co linearity (i.e highly correlated variables), so some variables were eliminated in order to eliminate multi-co linearity. The resulting analysis sifted out 22 variables out of the original 39 to leave 17. The latent root criterion suggested a four factor solution, which collectively accounted for $67.974 \%$ of the variance within the 17 variables. Furthermore, Cronbach's alpha as a 
diagnostic measure for consistency of the entire scale was utilized. The generally accepted lower limit for Cronbach's alpha to yield reliability is 0.70 (Addae-Dappah et al., 2009). Factors one and two satisfy this condition. However, since four variables were shown to account for the variance, these four factors are adopted for the study. We assume a variable belongs to a factor component with which it has the highest factor loading. Examining the variables belonging to each factor component, the attributed meanings to each factor may be expressed as shown in Table 4.

Thus, factor 1 was named as "Environmental-influenced Designs Features" with five variables, most of which could be used as environmental (design and construction) sustainability indicators (Table 1). These accounted for $19.75 \%$ of the total variance. Here, respondents showed that the weight attached to features such as connections to green space, condition of air conditioning plant, etc. (Table 3) could have a highly significant impact on the property to be valued. This indicates an awareness of environmental issues and carried an underlying assertion that a building with such features would attract higher market values.

The second group of variables clustering under factor 2 is collectively tagged: "cost-saving factors". These factors include variables such as accessible communication channels with building stakeholders; reduced water consumption; encouragement of employment of local residents within the building and productivity gains from compliance with health and safety. These factors accounting for $17.78 \%$ of the total variance represent opportunities to reduce operation costs through reduced overheads. Under normal conditions of sales, most of these factors constitute aspects of those 'economic' factors that enhance the value of a property through better local interactions and reduced government 'harassments' as a result of adherence to regulations. Thus, respondents agree that cost-saving factors have a significant weight in valuing for sustainability.

The third group of factors "social factors" covers the ability of occupiers to enjoy human capacity enhancements as a result of occupying the property. Admittedly, the variables under this factor reflect contemporary social problems. That is, local concern whereby any conflict that could compromise security of lives and property are forestalled, the need to ensure that man-made disasters (such as fire outbreak) do not affect the property. It is therefore not surprising that these contemporary social problems collectively account for $17.09 \%$ of the total variance.

In the valuation of conventional properties, locational factors are major factors to consider. Together with accessibility, locational factors place a premium value over other properties enjoying less locational advantage. In this study however, these factors accounted for the least variance amongst the four root criteria. Factors such as quality of overall built environment and site use, proximity to urban spaces (town centres, malls etc) and proximity to childcare facilities account for $13.3 \%$ of the variance. However, it is only in this factor that all variables display equally strong component values (see Table 3). It is possible to surmise from the component values of the variables that locational factors are themselves individually strong indicators in the valuation of sustainable properties.

To investigate the results in a more qualitative setting, we created five sustainability scenarios. Respondents were asked to indicate their 'subjective value' of the hypothetical property, to assess qualitatively, the weight attached to the social, economic and environmental features. The results are displayed as Table 5. The cohorts were made of five 'partially sustainable' cohorts and one unsustainable cohort as a control group. Explanatory indicators for each of the social, economic and environmental features were made available to respondents. Results show that in the first instance, respondents believed strongly that sustainability affects property value. This is to be seen in the fact that overall, respondents generally either believed that the existence of sustainable features will induce higher values or that the non-existence of sustainable features will induce lower market value. Only a few thought that taken side by side with a sustainable property, the non-existence of sustainable features will not reduce the market value of the property.

However, it was found that majority of the respondents (59.3\%) tended to believe more (at 59.3\%) that if a property is high on economic features, low on environmental features and low on social features; it would reflect higher property values. Also $57 \%$ felt that where a property is high on social features, low on economic features and low on environmental features; it would reflect higher market values. Moreover, $50 \%$ decided that where a property was low on economic features, high on environmental features and low on social features, it would also reflect higher market value. More respondents in the control group felt that the property not being sustainable will reflect lower market value. It is therefore suggested that sustainability affects property value. With this, the respondents' grasp of the sustainability question was further accentuated by the higher percentage of respondents ( $47.4 \%$ to $7.4 \%)$ who maintained that a property that is low on economic, low on environmental and low on social features will not be sustainable. On all scenarios, the least number of respondents believed that where these sustainable features are not present, it will not reduce the market value of the property. Respondents therefore believe that the existence of sustainable features would enhance the market value of a property, be it social, economic or environmental sustainability. However, taken with the results of the factor analysis above, it would appear that respondents would tend to define sustainability in terms of the social indicators rather than economic and physical features. This is because social features are rated consistently in both the qualitative and quantitative analyses. 
In the quantitative analysis, respondents' views clustered more around environmental features than any other, although if taken individually, economic variables achieved significant weights. Therefore, there is an appreciation of the economic aspect of sustainability. With the fact that the environmental variables achieved the highest clustering in the PCA; then there is also an appreciation of the environmental features of sustainability. The seeming disparity in the qualitative and quantitative analysis could be explained by the fact that a subjective element was introduced into the qualitative design. However, the readiness to accept that values would be positively affected by sustainability suggests that the hypothesis that Nigerian appraisers are not aware of sustainability features in properties can be rejected.

\subsection{Test of the Hypotheses}

To test the hypothesis that Nigerian valuers would tend not to utilize modern methods of valuation to account for sustainability features in properties; respondents were asked to indicate which of eleven suggested methods is considered most suitable in valuing a hypothetical sustainable property. From the results in Table 6, it appeared that respondent valuers were not specially inclined to either of the two categories of methodology. This could suggest a well-rounded knowledge of current practices in the relatively new field of valuing for sustainability. Reasons for this could include the fact that the respondents were predominantly young in practice and possibly more exposed, through information technologies and recent educational training to newer thoughts on valuation practice. Thus, the hypothesis that Nigerian valuers would tend not to utilize modern methods of valuation to account for sustainability features in properties is also rejected.

Respondents were also asked to indicate their level of familiarity with the required methods and to state whether they would like to have further training. In responding to the question 'which of these methods are you least familiar with? It was found that modern methods were rated higher and respondents were accordingly willing to receive more training in this area. This situation is to be taken as a positive one as it indicates that Nigerian valuers are willing to be exposed to new practices alongside their colleagues in other parts of the world. The hypothesis that Nigerian valuers do not require additional training to carry out sustainable valuation successfully is therefore rejected.

Respondents were thereafter asked to indicate and rank the foremost drivers for sustainability in the Nigerian property sector. This was done to ascertain whether respondents were aware of the potential role they (as real estate appraisers) could play in the drive to integrate sustainability into real estate investment decisions. The results in Table 8 showed that investors, property occupiers, property owners, government and estate surveyors and valuers were suggested as capable of influencing the adoption of sustainability in the Nigerian property industry. The role of government is perceived to be high. This is not surprising, given the high rate of government visibility in the built environment in this part of the world. It does validate the position that government has a crucial role to play in developing standards, rules and regulations that would support the drive to integrating sustainability in real estates.

\section{Conclusions}

Today, the real estate market represents one of the world's largest investment markets and property has been widely recognized as a distinct asset class (Lorenz, 2006). With the potential mainstreaming of sustainable development into real estate investment decisions, the challenge facing the industry as a whole is to ensure that property values and financial instruments are adjusted to reflect the true market value of sustainable buildings. Whether in the valuation of single sustainable property or valuation of properties in sustainable markets, property valuation has a key role to play in this transformation (Fibre, 2007). Lorenz (2006) laments that most valuations prepared today only contain environmental disclaimers as valuers claim no knowledge of environmental conditions by stating that the valuation of the property is made 'as clean'. This has to change. The challenge of creating, maintaining and managing sustainable human settlements has to be met by a set of core stakeholders whose decisions affect the shape, design and investment opportunities in the built environment. Appraisers have a significant role to play in meeting this challenge by influencing the market, by creating, where necessary, new methods or adapting old ones to meet the various appraisals needs of stakeholders - government, owners, occupiers, developers and financiers.

While it is recognized that appraisers should not lead values (Sayce et al., 2010), their influence on property investment decisions through the advice they provide is undeniable. Incorporating sustainability issues into valuations encourages market participants to see certain benefits of sustainable buildings reflected in the price estimates produced by valuers. The direct link between economic benefits and sustainability encourages them to achieve higher price estimates for the buildings they own or aim to sell. Valuers therefore have to know and account for sustainable features in properties and their ability to rise up to this challenge will determine the place of the valuation profession in a world that is getting increasingly aware of the social and environmental impacts of the property market.

\section{Recommendations}

Integrating sustainability issues into property valuation practice no doubt represents a great challenge for Nigerian valuers. Paucity of comparative data, limited application of commonly accepted standards, limited 
exposure of practitioners, weak regulatory framework, and paucity of research that should assists in determining and adjusting valuation variables to reflect sustainability are issues for concern. A drive towards the establishment of sustainability standards in the construction and management of properties would help to alleviate the problem of suitable data considerably. The provision of pre- and post qualification education for valuers and establishment of linkages between the academia and the industry are long-term activities that would enable valuers live up to this expectation (Sayce et al., 2010). The study suggests that, in addition to the need for specialized local knowledge, Nigeria real estate valuers have to develop the skills needed to operate in a globalised market, where his/her ability to value sustainably will be challenged by the body of rules existing in the local environment, some of which could be shaped by global standards.

Finally, the generally accepted accounting principles (GAAP) in the US and the adoption of International Accounting Standards Board (IASB) in the EU are both current and future external factors that would make it imperative for valuers to value for sustainability anywhere across the globe. The challenge for creating sustainability markets, sustainability indicators and sustainability valuation therefore seems to be one for global regulatory and professional bodies and we advocate that this challenge is taken up speedily to ensure the continued relevance of valuers in the drive for the creation and efficient operation of sustainable markets.

\section{References}

Addae-Dapaah, K., Liow Kim Hiang, \& Neo Yen Shi, S. (2009). Sustainability of sustainable real property development. Journal of Sustainable Real Estate.1.203-225.

Babawale, G. (2008). An Evaluation Of The Relative Impact of Factors Affecting Inaccuracy in Residential Property Valuation in Lagos Metropolis. (Unpublished doctoral Dissertation). University of Lagos, Lagos, Nigeria. Babawale, G., \& Koleoso, H. (2006). Real Estate Valuation Practice in Nigeria: Implication in a Globalizing World: Proceedings of an International Conference on the Built Environment: Innovation, Policy, and Sustainable Development held in Ota, (date). Ota, Nigeria: Covenant University.

Boyd, T. (2005). Can we assess the worth of environmental and social characteristics in investment property? Paper presented at 11th PRRES Conference, Melbourne, 23-27 January. Melbourne, Australia.

Boyd, T. and Kimmet, P. (2005). The Triple Bottom Line Approach to property performance evaluation, Paper Presented at PRRES, 23-27January. Melbourne, Australia.

Elliot P \& Warren, C. (2005). The valuation profession in Australia: profile, analysis and future directions Paper presented at 11th PRRES Conference, Melbourne, 23-27 January. Melbourne, Australia.

Fuerst, F., \& McAllister, P. (2010). What is the effect of eco-labeling on office occupancy rates in the USA? Findings in Built and Rural Environments Series. London: Royal Institute of Chartered Surveyors.

Goering J. (2009). Sustainable real estate development: The dynamics of market penetration. Journal of Sustainable Real Estate.1.168-201.

GVA-Grimley (2008). Corporate Real Estate Survey, London: GVA Grimley

Kauko, T. (2008). From modeling tools towards the market itself - an opportunity for sustainability assessment?, International Journal of Strategic Property Management, 12, $95 \quad-\quad 107$. http://dx.doi.org/10.3846/1648-715X.2008.12.95-107

Kimmet, P. (2006). Theoretical Foundations for Integrating Sustainability in Property Investment Appraisal: Paper presented at 12th Pacific Rim Real Estate Society Conference, Auckland, 22-25 January. Melbourne, Australia.

Lorenz, D. (2006). The application of sustainable development principles to the theory and practice of property valuations. (Unpublished Ph.D Thesis). Universidad Karlsruhe.

Lutzkendrof, T. and Lorenz, D. (2005). Sustainable property investment: valuing sustainable buildings through property performance assessment. Building Research \& Information 33,(3), 212-34.

Motta T.A., \& Endsley W.E. (2003). The future of the Valuation Profession: Diagnostic Tools and Prescriptive Practices for Real Estate Markets. Paper presented at the World Valuation Congress, Cambridge, United Kingdom.

Oven, D \& Pekdemir, A. (2006). Office rent determinants utilizing factor analysis. Journal of Real Estate Finance and Economics (33), 51-73. http://dx.doi.org/ 10.1007/s11146-006-8274-5.

Pearse, D. (2005). Do we understand sustainable development? Building Research and Information, Vol. 34(3) pp 201-207

Pivo, G. (2005). Is there a future for socially responsible property investment? Real Estate Issues, Fall, 16-26.

Pivo, G. (2007). Exploring responsible property investing: A Survey of American Executives. Corporate Social Responsibility \& Environmental Management. http://dx.doi.org/10.1002/csr.165 
Robinson, J. (2005). Property valuation and analysis applied to environmentally sustainable development. Paper presented In PRRES, 11th Pacific Rim Estate Society Conference 2005, Melbourne, 23-27. Australia: Melbourne.

Sayce, S., Sundberg, A., \& Clements., B. (2010). Is sustainability reflected in commercial property prices: an analysis of the evidence base. London: Royal Institute of Chartered Surveyors.

Sayce, S. Ellison, L. and Smith, J. (2004). Incorporating sustainability in commercial property appraisal: evidence from the UK', Australian Property Journal, August .226-233.

Zeemering, E. (2009). What does sustainability mean to city officials? Urban Affairs Review 45, 247-273. http://dx.doi.org/.1177/1078087409337297.

Notes

Note 1: During the pilot survey exercise for this study, respondents raised questions regarding the term 'green features', so it was decided to specify these terms as explicitly as possible to reduce questionnaire response time and improve clarity.

Table 1. Indicators for the triple-bottom line features of sustainable properties

\section{ENVIRONMENTAL (DESIGN AND CONSTRUCTION) INDICATORS}

Connections to designated green space

Suitability of original building materials for refurbishment and façade retention

Condition of air-conditioning plant

Ecological impacts of materials used for construction

Age of building (obsolescence or depreciation of materials)

Quality of overall built environment and site use in relation to aesthetics, visual blending and connection contribution of its street frontage and wider precinct

Public transport availability and standard of service

Maximization by property managers of the potential of the environmental design features

Compliance with Health \& Safety regulations and appropriate signage

Practical implications (traffic generation, off-street emergency parking and pedestrian management

Proximity to urban spaces (town centers, malls, etc)

Availability of appropriate internal circulation such as lifts and escalators

\section{ENVIRONMENTAL (GREEN) FEATURES}

Evidence of alternative energy supplies from renewable sources such as solar panels

Absence of indoor air pollutants net

Use of ODP or GWP refrigerants

Water consumption (potable, hygiene and cooling towers)

Fossil fuel energy use

Recycling and water capture measures

Indoor quality measured by ventilation, natural lighting, individual thermal/cooling control, noise abatement

Wastewater reduction

Disclosure and transparency of environmental data, regulation compliance, awards, and environmental expenditure of any type

Hazardous and non-hazardous waste and effluents recycling or removal strategies 


\section{ECONOMIC FEATURES}

Enhanced occupant productivity and health

Savings from reduced energy, water and waste

Adequate public liability and service provider insurance

\section{SOCIAL FEATURES}

Quality of communal service areas

Aesthetic implications

Wheelchair access

Awareness and training of emergency evacuation and

Accident first aid procedures for all floor warden

Complementary usage of building (compatible tenants)

Appropriate training for security and public relations personnel

Proximity to childcare facilities

Recognition of indigenous people through cultural space and communication of site history

Availability of first aid station accessible to all building users

Preservation of heritage values

Value of artwork as percentage of the fit out

Monitoring of stakeholder concerns, views and provisions

Supportive use and occupation guidelines for tenants

Nature of tenant businesses and naming rights

Transparency and disclosure of landlord/tenant contracts and marketing agreements

Source: Adapted from Boyd (2005)

Table 2. Characteristics of the Respondent Estate Surveyors and Valuers

\begin{tabular}{|c|c|c|}
\hline (n) & Frequency & Percentage $(\%)$ \\
\hline \multicolumn{3}{|l|}{ Gender of Valuers } \\
\hline Male & 109 & 68 \\
\hline Female & $\underline{51}$ & $\underline{32}$ \\
\hline $\begin{array}{l}\text { Total } \\
\text { (b) Academic Oualification }\end{array}$ & $\underline{160}$ & $\underline{100}$ \\
\hline Graduate (HND or B.Sc.) & 134 & 84 \\
\hline Others & $\underline{26}$ & $\underline{16}$ \\
\hline $\begin{array}{l}\text { Total } \\
\text { (c) Professional Qualification }\end{array}$ & $\underline{160}$ & $\underline{100}$ \\
\hline Registered Estate Surveyor \& Valuers & 128 & 80 \\
\hline Non -registered & $\underline{52}$ & $\underline{20}$ \\
\hline $\begin{array}{l}\text { Total } \\
\text { (d) Experience }\end{array}$ & $\underline{160}$ & $\underline{\overline{100}}$ \\
\hline $1-5$ years & 141 & 88 \\
\hline 6 and above & 19 & $\underline{12}$ \\
\hline $\begin{array}{l}\text { Total } \\
\text { (e) Geographical Distribution }\end{array}$ & $\underline{160}$ & $\underline{100}$ \\
\hline Ikeja, Lagos & 39 & 24 \\
\hline Lagos Island, Lagos. & 30 & 19 \\
\hline Victoria Island, Lagos & 25 & 16 \\
\hline Surulere, Lagos & 13 & 8 \\
\hline Other parts of Lagos & 21 & 13 \\
\hline Abuja & 21 & 13 \\
\hline Port Harcourt & 11 & 7 \\
\hline Total & $\underline{160}$ & $\underline{100}$ \\
\hline
\end{tabular}


Table 3. KMO and Bartlet's Test of Spherity

\begin{tabular}{lll}
\hline \multirow{3}{*}{ Bartlett's Test of Spherity } & Kaiser-Meyer-Olkin & .666 \\
\cline { 2 - 3 } & Approx. Chi-Square & 677.149 \\
\cline { 2 - 3 } & $\mathrm{df}$ & 139 \\
\cline { 2 - 3 } & Sig. & .000 \\
\hline
\end{tabular}

Table 4. Principal Component Analysis of Variables

\begin{tabular}{|c|c|}
\hline FACTORS & COMPONENTS \\
\hline 2 & 4 \\
\hline \multicolumn{2}{|l|}{ Factor 1: Environmental-influenced Designs Features } \\
\hline \multicolumn{2}{|l|}{ Cronbach's Alpha: 0.824} \\
\hline Connection to green space & 0.720 \\
\hline Condition of air conditioning plant & 0.758 \\
\hline Waste-water reduction & 0.697 \\
\hline Maximization of environmental design features & 0.615 \\
\hline Aesthetic implications & 0.772 \\
\hline Variance (\%) & 19.759 \\
\hline \multicolumn{2}{|l|}{ actor 2: Cost- saving factors } \\
\hline \multicolumn{2}{|l|}{ Cronbach's Alpha: 0.817} \\
\hline Evidence of alternative energy supplies from renewable sources & 0.824 \\
\hline Accessible communication channels with building stakeholders & 0.691 \\
\hline Reduced water consumption & 0.552 \\
\hline Encouragement of employment of local residents within the building & 0.565 \\
\hline Increased productivity from compliance with health $\&$ safety regulations & 0.799 \\
\hline Variance (\%) & 17.787 \\
\hline
\end{tabular}

Factor 3: Social Factors

Cronbach's Alpha: 0.630

\begin{tabular}{ll}
\hline Lighting power density \& peak energy demand & 0.774
\end{tabular}

Awareness and training of emergency evacuation and requirements in building design $\quad 0.804$

$\begin{array}{ll}\text { Complementary usage of building } & 0.570\end{array}$

$\begin{array}{ll}\text { Appropriate training for security personnel } & 0.122\end{array}$

$\begin{array}{ll}\text { Variance (\%) } & 17.099\end{array}$

Factor 4: Locational Factors Cronbach's Alpha: 0.648

\begin{tabular}{ll}
\hline Quality of overall built environment and site use & 0.743
\end{tabular}

$\begin{array}{ll}\text { Proximity to urban spaces (town centers, malls etc) } & 0.739\end{array}$

$\begin{array}{ll}\text { Proximity to urban childcare facilities } & 0.743\end{array}$

$\begin{array}{lr}\text { Variance(\%) } & 13,330\end{array}$

\begin{tabular}{lr} 
Total Variance (\%) & 67.974 \\
\hline
\end{tabular} 
Table 5. Qualitative Scenario Analysis

Cohorts

Sustainable: will reflect Not Sustainable: will Not sustainable: higher market value reflect lower market value this will not reduce the market value

\begin{tabular}{|c|c|c|c|c|c|c|}
\hline & & \multirow{2}{*}{\multicolumn{2}{|c|}{ Frequency $\%$}} \\
\hline & Frequency & $\%$ & frequency & $\%$ & & \\
\hline High on economic features & 80 & 59.3 & 38 & 28.1 & 7 & 5.2 \\
\hline
\end{tabular}

Low on environmental features

Low on social features

High on social features 77 57

41

$30.4 \quad 12$

Low on economic features

Low on environmental features

Low on economic features 68 50.4 54

$40 \quad 7$

High on environmental features

Low on social features

\begin{tabular}{lllllll}
\hline $\begin{array}{l}\text { High on economic features } \\
\text { Low on environmental features } \\
\text { High on social features }\end{array}$ & 60 & 44.4 & 47 & 34.8 & 22 & 16.3 \\
\hline $\begin{array}{l}\text { Low on economic features } \\
\text { Low on environmental features } \\
\text { Low on social features }\end{array}$ & 44 & 7.4 & 64 & 47.4 & 17 & 12.6 \\
\hline
\end{tabular}

Table 6. Appropriate Method of Valuation

\begin{tabular}{llcc}
\hline & & FREQUENCY & $\%$ \\
\hline Conventional & Comparative analysis & 64 & 59.8 \\
Methods & Profits & 89 & 83.2 \\
& Discounted cash flow method & 102 & 95.3 \\
& Residual method & 80 & 74.8 \\
& Contractors' method & 100 & 93.5 \\
& & & \\
Modern Methods & Hedonic pricing method & 91 & 85 \\
& Fuzzy logic & 86 & 90.7 \\
& Autoregressive integrative moving average & 97 & 87.9 \\
& Rough set theory & 94 & 100 \\
& Artificial neural network & 107 & 57.9 \\
\hline
\end{tabular}


Table 7. Level of Least Familiarity and Desire For Additional Training

\begin{tabular}{lll}
\hline & & $\%$ \\
\hline Conventional & Comparative analysis & 14 \\
Methods & Profits or Accounts method & 16 \\
& Discounted cash flow (DCF) method & - \\
& Residual method & 7 \\
& Contractors' method & 9 \\
Modern Methods & Hedonic pricing method & 9 \\
& Fuzzy logic & 45 \\
& Autoregressive integrative moving average & 16 \\
& Rough set theory & 16 \\
Special analysis & Artificial neural network & 21 \\
& & 25 \\
\hline
\end{tabular}

In this table, the percentages did not add up to exactly one hundred because some respondents chose more than one option

Table 8. Potential Drivers of Sustainability in Real Estates

\begin{tabular}{lccc}
\hline & $\begin{array}{l}\text { Most likely } \\
\text { (freq.\%) }\end{array}$ & $\begin{array}{l}\text { Probable } \\
\text { (freq.\%) }\end{array}$ & $\begin{array}{l}\text { Least likely } \\
\text { (freq.\%) }\end{array}$ \\
\hline Investors & 92.6 & 5.7 & - \\
Government & 63.8 & 25.4 & 0.8 \\
Property Occupiers & 86.7 & 34.4 & 14.8 \\
Estate surveyors \& valuers & 60.7 & 35.2 & 0.8 \\
Property owners & 69.7 & 26.2 & 3.3 \\
Civil society groups & 33.7 & 51.6 & 9.6 \\
Faith (religious) groups & 3.3 & 24.6 & 65.6 \\
\hline
\end{tabular}

